\title{
The embryonic development of Schistosoma mansoni eggs: proposal for a new staging system
}

\author{
Arnon D. Jurberg • Tiana Gonçalves • Tatiane A. Costa • Ana Carolina A. de Mattos • \\ Bernardo M. Pascarelli • Pedro Paulo A. de Manso - Marcelo Ribeiro-Alves • \\ Marcelo Pelajo-Machado • José M. Peralta • Paulo Marcos Z. Coelho • \\ Henrique L. Lenzi
}

Received: 29 September 2008 / Accepted: 3 April 2009/Published online: 5 May 2009

(C) Springer-Verlag 2009

\begin{abstract}
Schistosomiasis is a water-borne parasitic illness caused by neoophoran trematodes of the genus Schistosoma. Using classical histological techniques and whole-mount preparations, the present work describes the embryonic development of Schistosoma mansoni eggs in the murine host and compares it with eggs maintained under in vitro conditions. Two pre-embryonic stages occur inside the female worm: the prezygotic stage is characterized by the release of mature oocytes from the female ovary until its fertilization. The zygotic stage encompasses the migration of the zygote through the ootype, where the eggshell is formed, to the uterus. Fully formed eggs are laid still undeveloped, without having suffered any cleavage. In the outside environment, eight embryonic stages can be defined: stage 1 refers to early cleavages and the beginning of yolk fusion. Stage 2 represents late cleavage, with the formation of a stereoblastula and the
\end{abstract}

Communicated by D. A. Weisblat

Electronic supplementary material The online version of this article (doi:10.1007/s00427-009-0285-9) contains supplementary material, which is available to authorized users.

A. D. Jurberg $(\bowtie) \cdot$ T. Gonçalves $\cdot$ T. A. Costa $\cdot$

B. M. Pascarelli • P. P. A. de Manso $\cdot$ M. Pelajo-Machado •

H. L. Lenzi $(\bowtie)$

Laboratório de Patologia, Instituto Oswaldo Cruz (IOC)/Fundação

Oswaldo Cruz (Fiocruz),

Pavilhão Gomes de Faria. Av. Brasil, 4365-Manguinhos,

CEP: 21040-900 Rio de Janeiro, RJ, Brazil

e-mail: ajurberg@igc.gulbenkian.pt

e-mail: henrique.lenzi@gmail.com

A. C. A. de Mattos P. P. M. Coelho

Laboratório de Esquistossomose,

Instituto René Rachou (CPqRR)/Fiocruz,

Belo Horizonte, MJ, Brazil onset of outer envelope differentiation. Stage 3 is defined by the elongation of the embryonic primordium and the onset of inner envelope formation. At stage 4, the first organ primordia arise. During stages 5 to 7 , tissue and organ differentiation occurs (neural mass, epidermis, terebratorium, musculature, and miracidial glands). Stage 7 is characterized by the nuclear condensation of neurons of the central neural mass. Stage 8 refers to the fully formed larva, presenting muscular contraction, cilia, and flame-cell beating. This staging system was compared to a previous classification and could underlie further studies on egg histoproteomics (morphological localizome). The differentiation of embryonic structures and their probable roles in granulomatogenesis are discussed herein.

Keywords Schistosoma mansoni $\cdot$ Egg · Embryo · Development $\cdot$ Platyhelminth

\section{Ribeiro-Alves}

Centro de Desenvolvimento

Tecnológico em Saúde (CDTS)/Fiocruz,

Rio de Janeiro, RJ, Brazil

\section{J. M. Peralta}

Instituto de Microbiologia/Universidade

Federal do Rio de Janeiro,

Rio de Janeiro, RJ, Brazil

Present Address:

A. D. Jurberg • T. Gonçalves

Instituto Gulbenkian de Ciência,

Rua da Quinta Grande 6,

2781-901 Oeiras, Portugal 


\section{Introduction}

Human infections caused by trematode worms of the genus Schistosoma are generally referred to as "schistosomiasis." Schistosoma mansoni displays a wide distribution and thus is considered one of the principal etiological agents (Chitsulo et al. 2000; WHO 2006). Unlike other platyhelminths, schistosomes have separate sexes and can reside as couples for years within susceptible vertebrates. Inside the host vasculature, each inseminated adult female releases about 300 encapsulated embryos per day (Moore and Sandground 1956; Pellegrino and Coelho 1978). Taking into consideration terminological discrepancies between parasitologists and developmental biologists, the term "egg" will be used hereinafter to designate these embryos retained within a protective covering, which will be referred as "eggshell." In brief, laid eggs mature within the host tissues and are subsequently carried by the bloodstream into smaller blood vessels of several organs, where they are trapped. Should the eggs reach the intestines, they may induce an inflammatory periovular reaction and be expelled into the intestinal lumen (Lenzi et al. 1987, 1991). This process allows the parasite to undergo the next stage in its life cycle whereby ciliated larvae hatch from eggs when infected feces reach freshwater. These so-called miracidia must localize and penetrate an intermediate host snail of the genus Biomphalaria (e.g., Ottolina 1957; Chernin 1970, 1974; Haberl et al. 1995). Within the mollusk host, miracidia undergo cycles of asexual reproduction leading to the emergence of cercariae, which are able to infect humans (e.g., Maldonado and Acosta-Matienzo 1947; Coelho 1957; Pan 1996; reviewed by Coelho et al. 2008). Cercariae actively swim towards susceptible hosts and penetrate their skin (e.g., Saladin 1982; Haas et al. 1994), where a second set of morphological changes (with no reproduction) starts and will give rise to schistosomula and then adult worms (e.g., Stirewalt 1974; McLaren 1980; reviewed by Wilson 1987 and Lenzi et al. 2008).

Schistosome eggs are considered a major cause of liver injury and illness. About half of the laid eggs lodge in the liver sinusoids, where they act as granulomatogenic triggers and eventually die (Warren 1978). Granuloma formation is strictly dependent on viable mature eggs (Sorour 1929; Espin 1941), not occurring around single immature eggs (Prata 1957). Recently, Ashton et al. (2001) suggested that the secretion of egg proteins to periovular tissues may be related to the formation of eggshell underlying structures during egg maturation. These structures are widely known in the schistosome community as the Reynold's layer and the von Lichtenberg's envelope (Neill et al. 1988). However, as stated by Swiderski (1994), the use of such distinct terminology is not justified since these envelopes share ontogenetic, structural, and functional similarities to other platyhelminth eggs (for example, Cestodes). Therefore, further references to the schistosome eggshell structures in this paper will consider their positions within the egg. The Reynolds' layer will be referred as the "outer envelope" and the von Lichtenberg's envelope as the "inner envelope."

Despite its importance in pathogenesis and life cycle continuity, egg embryogenesis investigations have mainly focused on the surrounding envelopes, most likely due to technical limitations (see Jurberg et al. 2008b). No information on the miracidial organogenesis is available so far. Maturation of schistosome eggs was first classified into five stages based on a simple relation between the embryo and the eggshell sizes (Vogel 1942; Prata 1957). Here, Vogel and Prata's classic staging system will be referred in roman numerals: at stage I, the embryo occupies one third of the diameter of the egg; at stage II egg, the embryo occupies one half of the diameter of the egg; at stage III, the embryo is two thirds of the length of the egg; at stage IV, the embryo almost occupies the entire interior of the egg; stage $\mathrm{V}$ corresponds to the mature embryo, presenting both cell-flame and cilia beating and muscle contractions. Pellegrino's group have adapted this staging system to the "oogram" technique by calculating the frequency of occurrence of each stage in compressed fragments of intestine as a reliable criterion for the primary screening of schistosomicidal drugs (Pellegrino et al. 1962; Cunha et al. 1962; Pellegrino and Faria 1965).

Recently, Hartenstein and Ehlers (2000) have introduced a different staging system for the free-living rhabdocoel Mesostoma lingua. This system considers morphological events during its embryogenesis and has shown to be applicable for other free-living flatworms (Younossi-Hartenstein et al. 2000; Younossi-Hartenstein and Hartenstein 2000b, 2001; Ramachandra et al. 2002; Hartenstein and Jones 2003; Morris et al. 2004; Cardona et al. 2005, 2006). Stage 1 refers to early cleavages, during which the zygote divides in a spiral pattern. Stage 2 represents late cleavage, in which a proliferating mass (the embryonic primordium) is formed. Stage 3 is defined by the expansion and diversification of the embryonic primordium. At stage 4, some embryonic primordia can be distinguished. Stage 5 is characterized by the onset of tissue and organ differentiation. At stage 6, the complete formation of the epidermis occurs. During stage 7 , the elongation of the embryo takes place and the neural mass ("brain") primordium condenses. Finally, stage 8 refers to the fully formed mature larva.

In the present paper, we describe the morphological events during $S$. mansoni egg embryogenesis by using histological and whole-mount techniques. Since S. mansoni mature larvae (miracidia) have no eyespots and digestive system (Pan 1980), morphological hallmarks were determined by analyzing whole-mount miracidia prior to study 
egg development. Therefore, a new staging system (in Arabic numerals) is proposed and then further correlated to the previous existing one by Vogel (1942) and Prata (1957). Egg development under in vitro conditions was also evaluated.

\section{Materials and methods}

Parasites

Five-day-old Swiss Webster mice were exposed to 70 or 150 cercariae of $S$. mansoni (LE strain) and euthanatized in a $\mathrm{CO}_{2}$ chamber at 45-60 days after infection, in accordance to the Ethical Committee for Animal Use Fiocruz (CEUA L-0013/07). Adult worms were recovered by direct incisions of the portal hepatic intestinal system or as described by Kusel et al. (2006). Miracidia were obtained from blended livers by using a modified hatching method as described previously (Jurberg et al. 2008a). Eggs were isolated by sieving homogenized intestines (Dresden and Payne 1981) followed by purification through a Percoll gradient (Dalton et al. 1997).

\section{Histology}

Intestines and livers from infected mice were fixed in Carson's modified Millonig's phosphate-buffered formalin (CMF; Carson et al. 1973), pH 7.4, and embedded in paraffin. Recovered female worms fixed in a 70\% alcoholformalin-acetic acid solution (AFA; $95 \mathrm{ml}$ of 70\% ethanol, $3 \mathrm{ml}$ of $40 \%$ aqueous formaldehyde, and $2 \mathrm{ml}$ of glacial acetic acid) and embedded in paraffin were also processed as follows. Serial sections of $5 \mu \mathrm{m}$ were stained by the following methods for bright field microscopy (BM): hematoxylin and eosin (H\&E) and Lennert's Giemsa (Lennert 1978) for cellular characterization, periodic acidSchiff counterstained with hematoxylin (PASH) for neutral polysaccharides and glycoproteins (Lillie and Fullmer 1976), PAS-Alcian Blue pH 1.0 (PAS-AB) for differentiating between neutral glycoproteins and proteoglycans with different levels of sulfate groups, and Masson trichrome for collagen and smooth muscle (Bancroft and Stevens 1996).

In vitro attainment of eggs

To compare the maturation of eggs laid in vitro and eggs isolated from the murine host (as described above), adult worms were recovered by perfusion and maintained under in vitro conditions for the attainment of eggs (Kusel et al. 2006). Development was followed every day under an inverted microscope, until the complete formation of the miracidium. Miracidium maturity was inferred by movements inside the eggshell, muscle contractions, and flame-cell beating (Prata 1957). Other cultivated eggs at different times of maturation were fixed in CMF for whole-egg analysis.

Measurement of egg growth and statistical analysis

On each day of incubation, eggs laid in vitro were collected and mounted on regular flat slides using solid Vaseline as a spacer. For comparison between egg growth under in vitro and in vivo conditions, isolated eggs from the murine host were also analyzed. Eggs were classified in accordance with Vogel and Prata's staging system due to the lack of morphological resolution when analyzed as unstained whole mounts by BM. As this staging system is based on the ratio of egg size to the embryo itself, the area of the egg was defined as a simple character to compare the embryonic development between each stage under these two different conditions. At random, 30 eggs in each stage of maturation obtained using these two conditions were measured (length and width) at $\times 100$ magnification using the KS300 software 3.0 (Zeiss), measuring 300 eggs in total (Table S1). The area $A$ of each egg was estimated by considering its longest length (major axis) and its longest width (minor axis), in accordance to the area formula of an ellipse: $A=$ $(\Pi \times$ major axis $\times$ minor axis $) / 4$. An analysis of variance, two-way analysis of variance, followed by Tukey's post hoc test was carried out in the R software (R Development Core Team 2008). See "Supplementary methods" for additional information. Statistical significance was set as $P \leq 0.05$.

\section{Whole-mount analysis}

Adult female worms, miracidia, and eggs were all stained in hydrochloric carmine for confocal microscopy. Female worms were fixed in AFA and processed as described by Machado-Silva et al. (1998). Miracidia and eggs were fixed in $\mathrm{CMF}$ and processed within conical centrifuge tubes. Staining procedures were modified based on a previous work (Jurberg et al. 2008b). In brief, fixed eggs were stained overnight in carmine under agitation, dehydrated in graded ethanol series, and mounted as whole preparations in ethylene glycol between depression slides and coverslips. Tomographic images were obtained by confocal laser scanning microscopy (CLSM; LSM 510-META, Zeiss). Abnormal and dead (semitransparent, without embryonic disc, or granular) eggs were not examined.

The oogram technique by CLSM

The oogram technique was first described by Pellegrino et al. (1962). We present a modification of this procedure 
to allow the observation of morphological details during egg maturation. Murine intestinal fragments of $0.5 \mathrm{~cm}$ were cut off, slightly dried in absorbent paper, and maintained strongly pressed between glass slides with rubber bands during fixation overnight in $70 \%$ ethanol under agitation. Top slides were removed and flattened samples were stained overnight in carmine under agitation, at room temperature. The samples were dehydrated, mounted, and analyzed by CLSM as mentioned for isolated eggs.

Muscle labeling

Murine-infected intestines and livers were embedded in Tissue-Tek O.C.T. compound (Sakura Finetek, USA) and frozen by immersion in liquid nitrogen. Sections of 5$7 \mu \mathrm{m}$ were cut on a cryostat and fixed in acetone for $15 \mathrm{~min}$ at $-20^{\circ} \mathrm{C}$. Then, they were washed in phosphatebuffered saline (PBS) and incubated for $1 \mathrm{~h}$ in tetramethylrhodamine-isothiocyanate-conjugated phalloidin in PBS (Sigma). An antimouse monoclonal antibody previously characterized (Peralta 1986) was also used in conjunction with the Animal Research Kit (Dako), with modifications for immunofluorescence (Gonçalves 2008). After washing in PBS, the sections were coverslipped in buffered glycerin with $p$-phenylenediamine and analyzed under CLSM.

\section{Results}

Miracidium morphology by CLSM

Whole-mounted carmine-stained miracidia were analyzed by CLSM to define internal organs aiming to classify the embryonic development of the eggs. Histological sections of mature eggs in the small intestine were also considered. The following structures were easily detected by both methods: (1) central neural mass, (2) lateral glands, (3) apical gland, (4) terebratorium, (5) ciliated tegument, and (6) germ cells. Although evident in the miracidium, germ cells were not considered as a reference feature due to their similarity with early immature cells (blastomeres). They possess large round nucleus, prominent nucleolus, and scarce cytoplasm (Fig. 1a-d). Fine detailed information on the miracidium morphology can be found in the ultrastructural study by Pan (1980).

Female reproductive system and intrafemale egg development

Only a brief period of the egg development occurs inside the female reproductive system. Our findings on the

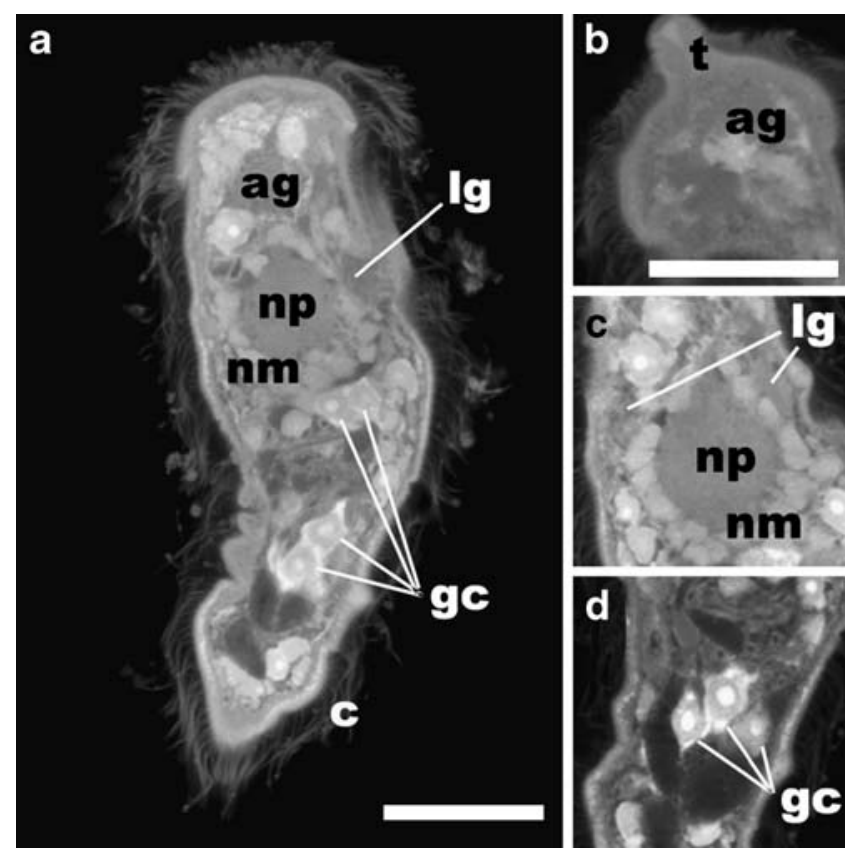

Fig. 1 Miracidial morphology by confocal laser scanning microscopy (CLSM). Virtual sections in ventral view of the same whole-mounted miracidium stained with hydrochloric carmine. a Panoramic view of an intermediate plane. b Detail of the anterior region, showing the terebratorium $(t)$ and the apical gland $(a g)$. c Detail of the central neural mass $(\mathrm{nm})$ flanked by the lateral glands $(\mathrm{lg})$. d Detail of posterior region, showing three germ cells $(g c) . n p$ neuropile; $c$ cilia. Scale bars $20 \mu \mathrm{m}$

female reproductive system are in accordance to Neves et al. (2005), although the morphology of the Mehlis' gland was not evaluated in this investigation. Regarding egg formation, two stages can be defined. In the brief prezygotic stage, single oocytes left the ovary by projecting their cytoplasms (pseudopods; Fig. 2a). Each oocyte is fertilized in the seminal receptacle and develops to the zygotic stage (also named as stage 0 ). In this stage, the zygote passes through the oviduct and the vitellineoviduct, where it is surrounded by approximately 40-45 vitelline cells (vitellocytes). Vitelline cells are smaller than the zygote and present a central, eosinophilic nucleus, and azurophilic cytoplasm full of blue-stained yolk granules by Giemsa. In PASH and Masson's trichrome-stained sections, the vitelline cell cytoplasm was slightly eosinophilic with weakly red and green-blue tinge, respectively. The zygote plus the surrounding vitelline cells are pushed by the female muscular contractions to enter the ootype, where the eggshell is formed (Fig. 2b). The fully formed egg with its characteristic conspicuous lateral spine is then released into the uterus (Fig. 2c). Finally, the egg is released through the gonopore to the external environment, without presenting any cleavage as observed in newly laid eggs in vitro (Fig. 2d). 

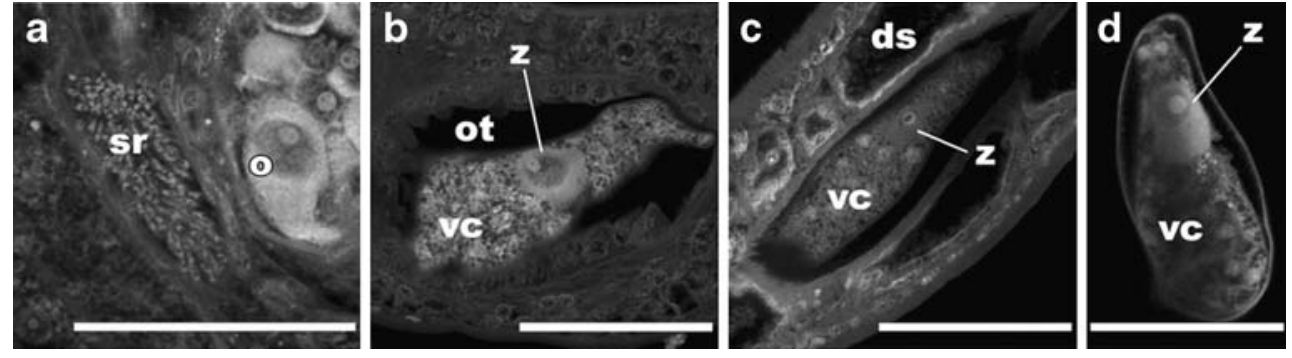

Fig. 2 Intrafemale egg development. a-c Confocal laser scanning microscope images of entire females stained with hydrochloric carmine. d In vitro laid egg stained with hydrochloric carmine. a Detail of a mature oocyte leaving the ovary by projecting a pseudopod. b Eggshell formation in the ootype (ot). This zygote was surrounded by 40 vitelline cells. c Egg in the uterus. This egg has 45

Stages in S. mansoni egg embryogenesis

\section{Stage 1}

Newly laid eggs are passively carried by the blood flow until they are trapped in small vessels of the murine host. At the onset of this stage (also corresponding to Vogel and Prata's stage I), the embryo was too small and difficult to be visualized in whole eggs (see Fig. 8a). Carmine-stained eggs by CLSM and histological sections revealed that the first cleavage was total and subequal, producing two blastomeres slightly different in size (Fig. 3a). They showed a central large round nucleus, homogeneously stained but lacking heterochromatin delineation ("ground glass" aspect), with a very prominent and intense basophilic nucleolus. Nucleolar inclusions were visualized by BM. The cytoplasm was abundant and homogeneously blue when stained with PASH and Giemsa (Figs. 3a, b). These features indicate that the cells were actively engaged in protein synthesis. Embryonic cells were difficult to see on PAS-AB-stained slides due to the very weak staining of both nucleus and cytoplasm (Fig. 7a). Vitelline cells exhibited an apparently vacuolated cytoplasm, slightly stained in red by PASH (Fig. 3a) and in green-blue by Masson trichrome (Fig. 3c), but highly red in PAS-ABstained slides (Fig. 7a). This staining pattern suggests the presence of neutral polysaccharides or neutral glycoproteins. As soon as the first cleavages occur, the vitelline cells started to fuse into a single yolk syncytium. The remnant vitelline nuclei were small, basophilic, irregularly shaped (Fig. 3). Following cleavages occurred asynchronously, resulting in the formation of the animal-vegetal axis. By the end of stage 1, the embryo formed a roughly circular disc, two to three cells in diameter (Fig. 3d). The embryonic primordium now became visible in the center of the whole unstained eggs as a clear disc, occupying about the half of the transversal length of the egg (now corresponding to Vogel and Prata's stage II; Fig. 8). vitelline cells. Vitelline cells were counted in virtual three-dimensional tomographies. d Early laid egg in culture. Notice no cleavage during intrafemale egg development. Plasma membranes seem to disappear progressively. $z$ zygote; $d s$ digestive system; $s r$ seminal receptacle full of sperm. Scale bars $50 \mu \mathrm{m}$

Stage 2

The embryonic primordium increased in size (Figs. 3e- $\mathrm{h}$ and 8). The number of embryonic cells, visible in whole eggs stained by carmine and analyzed by CLSM or in histological sections, reached four to six cells wide and six to eight cells long (Fig. 3e-h and S5d). Embryonic cells and the yolk syncytium remained morphologically similar to the previous stage (Fig. 3a-h). Mitotic figures were visualized throughout the embryo (Fig. 3g, h). Other cells presented pycnotic nuclei in PASH-, Giemsa-, and Masson trichromestained sections (Fig. 3g, h), suggesting the occurrence of apoptosis during early embryonic development. Vitelline cells fused completely. Three to four macromeres seemed to detach from the embryo poles, adhering to the eggshell. These cells will give rise to the outer envelope of the egg (Fig. 3g). These macromeres had a large round nucleus, with "ground glass" aspect (slightly heterochromatic). The nucleolus was round, intensely basophilic, and very prominent, with a punctiform light nucleolar inclusion. Their cytoplasm was scarce and apparently basophilic, being stained in blue by $\mathrm{H} \& \mathrm{E}, \mathrm{PASH}$, and Giemsa (Fig. 3g). Some vitelline nuclei also seemed to adhere to the eggshell. By the end of stage 2, a solid proliferating cell mass (stereoblastula) occupied the whole transversal length of the egg (corresponding also to Vogel and Prata's stage II; Figs. $3 \mathrm{~h}$ and 8 ).

\section{Stage 3}

A clear cellular mass corresponding to the embryo increased in size, assuming an elongated form, that occupied two thirds of the longitudinal length of the egg (similar to Vogel and Prata's stage III; Figs. 3i-1 and 8). Eggs were significantly bigger than in the previous Vogel and Prata's stage (Fig. 8; see Supplementary results; Table S2; Figs. S4 and S5e). In histological sections, the yolk syncytium remained heavily stained in red by PAS-AB, 

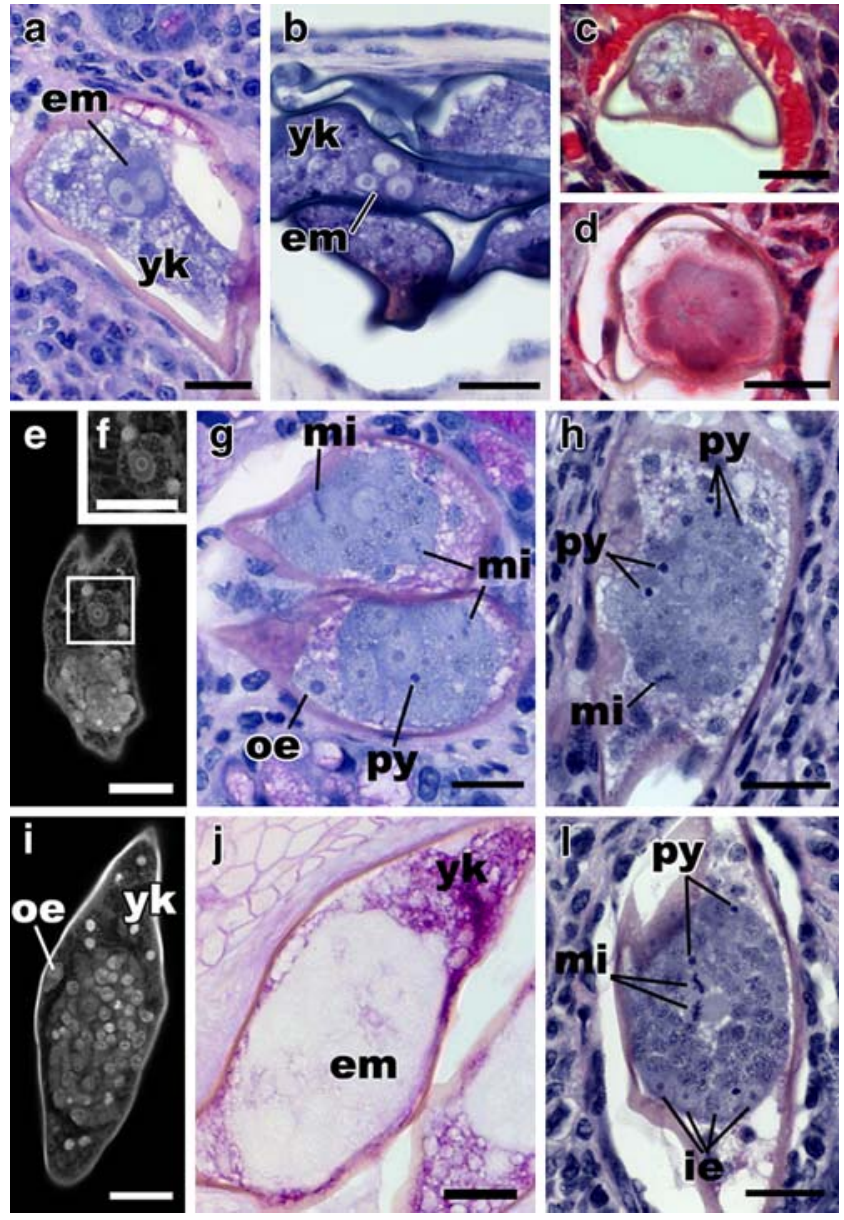

Fig. 3 Early stages of $S$. mansoni embryonic development. a-d, $\mathbf{g}, \mathbf{h}, \mathbf{j}$, I Bright field micrographs of eggs in the intestine of the host. $\mathbf{a}, \mathbf{g}, \mathbf{h}$, I PASH staining. b Lennert's Giemsa staining. c, d Masson trichrome staining. j PAS-AB pH 1.0 staining. e, f, i Confocal laser scanning microscope images of whole-mounted eggs stained with hydrochloric carmine. Both eggs were obtained from the host. a-d Stage 1, early cleavage. Embryonic cells $(\mathrm{em})$ in early cleavage. The surrounding vitelline cells are fused. c Detail of the vitelline cells stained in green. Cytoplasm is rich in vacuoles. d Transversal section of the vegetal pole, showing six macromeres. e-h Stage 2, late cleavage. The embryonic disc $(\mathrm{em})$ increases in size, occupying one half of the diameter of the egg. e Virtual section of a whole egg, showing the stereoblastula. i Detail of $\mathbf{h}$ (inset). A highly vacuolated vitelline cell in degradation process. $\mathbf{g}-\mathbf{h}$ The stereoblastula exhibits several mitotic figures $(m i)$ and pycnotic nuclei $(p y)$. Macromeres detach from the embryo and adhere to the eggshell, giving rise to the outer envelope (oe). i-l Stage 3. The embryonic disc $(\mathrm{em})$ elongates. i Virtual section of a whole egg reveals at least two types of cells (considering the nuclear morphology) and the outer envelope (oe). $\mathbf{j}$ A marked difference in the staining pattern between the embryonic cells and the yolk syncytium is evident. Yolk $(y k)$ is stained with the PAS reaction, indicating a rich neutral glycoconjugate content. I The embryo still exhibits several mitotic figures $(m i)$ and some pycnotic nuclei $(p y)$. At one pole, some cells seems to be committed with the inner envelope (ie) differentiation. Scale bars $20 \mu \mathrm{m}$ while the embryo itself remained difficult to be visualized. Cellular differentiation began, giving rise to at least two types of cells (Figs. 3i, 1; Video S1). Type I cells preserved the immature morphology, presenting a large round nucleus, with "ground glass" aspect, prominent nucleolus, and scarce cytoplasm, stained in blue by Giemsa. Type II cells (possibly neuroblasts) seemed to be concentrated in the center of the embryo. They had small slightly irregular nucleus, with a close chromatin pattern, and scarce cytoplasm. The nucleus was slightly stained green-blue by Masson trichrome, and a punctiform nucleolus was evident. The embryo presented approximately seven to ten cells wide and nine to 12 cells long (Fig. 3i-1; Video S1). Several mitotic figures were seen at this stage throughout the embryo (Fig. 31). Signs of apoptosis as pycnotic nuclei were present mainly in the periphery of the embryo (Fig. 31). Other peripheral embryonic cells seemed to be committed with the differentiation of the inner envelope. Their nuclei were slightly flattened (Fig. 31). In the outer envelope, differentiation initially started at stage 2 with the adhesion of macromeres to the eggshell. Subsequent syncytium formation seemed to continue with the fusion to the yolk syncytium.

\section{Stage 4}

In relation to the previous stage, it was not possible to distinguish morphological changes in whole unstained eggs (corresponding to Vogel and Prata's stage III; Fig. 8). In histological sections, the differentiation of the inner envelope became apparent with the formation of a detaching syncytium surrounding the whole embryo (Figs. 4a-c). The cytoplasm of these cells were lightly stained in red by PAS-AB-staining, while the yolk mass was highly colored and the embryo itself was barely stained (Fig. 7b). The inner envelope syncytium was also stained in red by PASH, while its cytoplasm was colored in blue by Giemsa, suggesting a scattered distribution of ribosomes (Fig. 4a). The flattened nuclei remained with their "ground glass" aspect, with a pronounced lateral nucleolus. The outer envelope was fused to the yolk syncytium and seemed to disappear progressively during development (Fig. 4a). These events were also visualized in whole carmine-stained eggs by CLSM (Fig. 4b). Vitelline nuclei were visible at the poles of the egg. In the center of the embryo, the neural mass primordium (central neural mass) arose from a roughly spherical group of cells with small heterochromatic nuclei and punctiform nucleoli (type II cells). These neural precursors were arranged in a layer of one to two cells thick around an acellular region (neuropile). By Masson trichrome, such nuclei stained slightly in blue-green (Fig. 4c). Immature cells (type I cells) were mainly concentrated in the periphery of the embryo (Fig. $4 \mathrm{a}-\mathrm{c}$ ). 

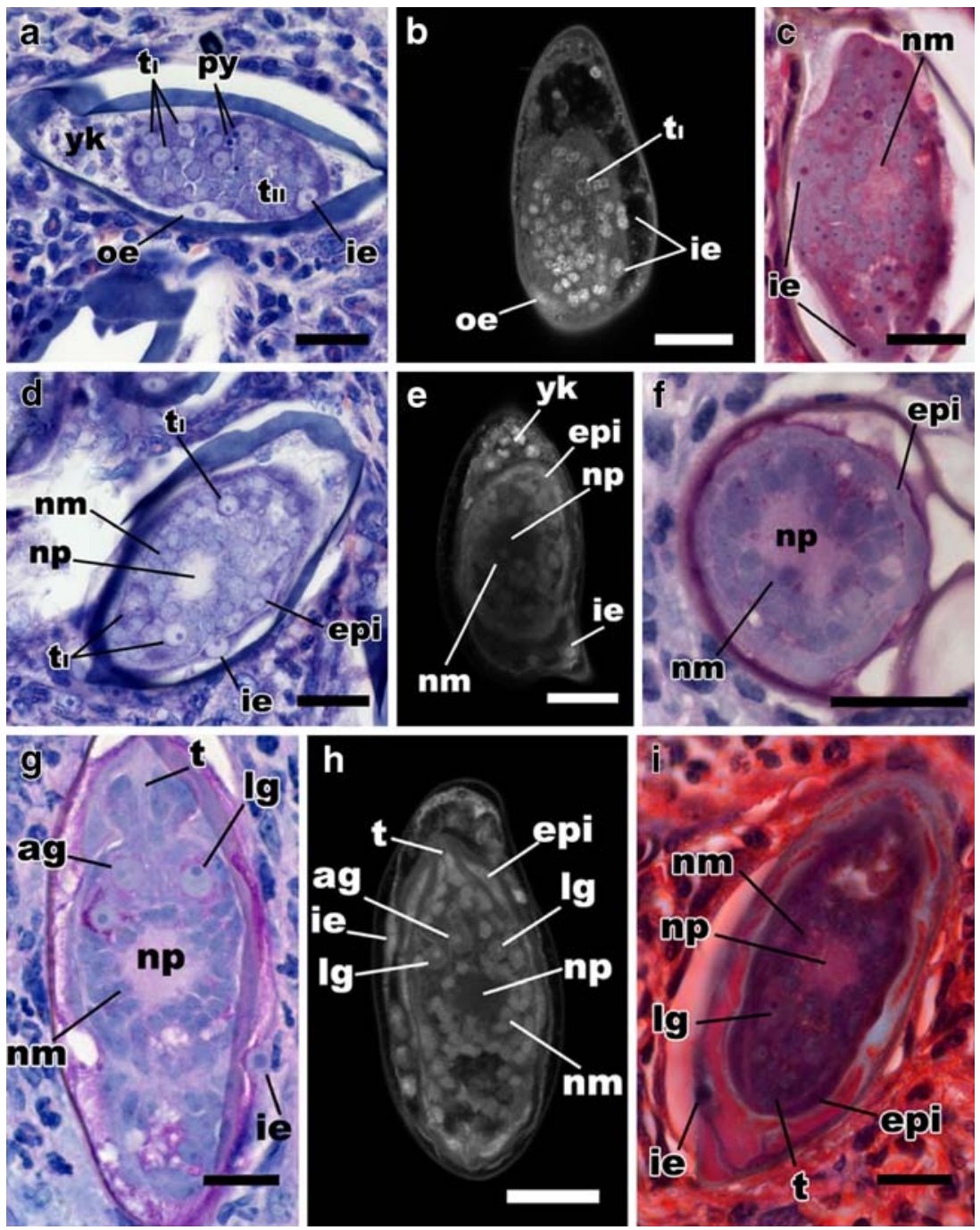

Fig. 4 Organogenesis of $S$. mansoni eggs. a, c, d, f, g, i Bright field micrographs of eggs in the intestine of the host. a, d Lennert's Giemsa staining. f, g PAS-AB pH 1.0 staining. c, i Masson trichrome staining. $\mathbf{b}, \mathbf{e}, \mathbf{h}$ Confocal laser scanning microscope images of whole-mounted eggs isolated from the murine host $(\mathbf{b}, \mathbf{h})$ or obtained from culture (e) and stained with hydrochloric carmine. a-c Stage 4. Parasagittal sections of the embryo reveal the differentiation of the inner envelope (ie) and at least two types of cells $\left(t_{I}\right.$ and $\left.t_{I I}\right)$. Type II cells are probably differentiating neuroblasts and concentrate in the interior of the embryo, while type I cells correspond to the immature ones. In a, the outer envelope (oe) seems to fuse with the yolk $(y k)$. Pycnotic nuclei ( $p y)$ are also visible. c Parasagittal section of the embryo reveals the differentiation of the neural mass primordium $(\mathrm{nm})$ with an acellular central region, called neuropile $(n p)$. Notice the neuroblast nuclei stained in green by Masson trichrome. d-f Stage 5 . The embryo occupies almost the entire egg. Some yolk is located in the poles. d, e Parasagittal sections of the embryo show the neural mass primordium

\section{Stage 5}

The embryo occupied almost all the internal area of the egg, although some vitelline remnants were still present in the poles (corresponding to Vogel and Prata's stage IV; Figs. $4 \mathrm{~d}-\mathrm{f}$ and 8 ). Both cultivated and isolated eggs also $(\mathrm{nm})$ and its acellular neuropile (np), the inner envelope (ie) and the onset of epidermis (epi) formation, by the fusion of some peripheral cells. Type I cells $\left(t_{I}\right)$ are spread mainly at the poles of the embryo. They will give rise to the miracidial glands and to the germ cells. $f$ Transversal section of the embryo, detaching the neural mass primordium $(n m)$, its neuropile $(n p)$, and the syncytial epidermis primordium (epi). The neuropile $(n p)$ has a slight staining in red by PASH. g-h Stage 6. Parasagittal sections of the embryo reveal the differentiation of miracidial glands and of the terebratorium $(t)$. g Just above the neural mass primordium $(\mathrm{nm})$, two laterally located type I cells start to produce PAS-positive cytoplasmic granules and will give rise to the lateral glands $(\lg )$. More anteriorly, other three type I cells also produce PAS-positive granules and will fuse to form the apical gland (ag). The inner envelope (ie) is also positive to the PAS reaction. $\mathbf{h}$, i The epidermis (epi) is almost fully formed, but no underlying musculature and cilia were observed by CLSM nor revealed by the Masson trichrome staining (see i). Scale bars $20 \mu \mathrm{m}$

increased in size as development proceeded (Fig. 8; see Supplementary results; Table S2; Fig. S4). The outer envelope assumed a thin, granular, and anucleate aspect, making its visualization on histological sections difficult. The inner envelope was highly stained in red with PASH and PAS-AB, maintaining its syncytial aspect (Fig. 4f). The 
neural mass primordium increased in size, expanding its central and acellular region (Fig. 4d-f). The epidermis started to differentiate from the most peripheral cells of the embryo, consisting of small cuboidal primordial cells which fused with one another to form another syncytium just beneath the inner envelope (Fig. 4d-f). Such epidermal primordium had round nuclei without evidence of heterochromatin delineation ("ground glass" aspect). Its basophilic cytoplasm stained in blue by Giemsa indicates an active engagement in protein synthesis (Fig. 4d). In the anterior region of the embryo, two large immature cells appeared on each side of the neural mass primordium.

\section{Stage 6}

Based on Vogel and Prata's classification, no differences were identified between this stage and the previous one when analyzing whole unstained eggs. The lateral anterior immature cells exhibited cytoplasmic granules which were highly PAS positive (Fig. 4g). The nuclei remained large and round, without heterochromatin delineation and nucleoli were prominent. These immature cells were the precursors of the lateral glands of the miracidium. An anterior group of other immature small cells presented a lighter cytoplasmic positive staining to the PAS reaction (Fig. 4g). This group will form the apical gland of the mature larvae. The epidermis of the anterior region of the embryo seemed to project onwards, defining a cone-like structure, called terebratorium (Figs. 4g-i; Video S2). The neuropile of the neural mass primordium exhibited a light positive stain to PAS, similar to that of the embryonic parenchyma (Fig. 4g). In the midposterior region of the embryo, groups of three to five cells with immature features appeared (large round nucleus with "ground glass" aspect and scarce basophilic cytoplasm) that correspond to the germ cells of miracidia (Video S2). The inner envelope showed the same features of the previous stages, with large round "ground glass" nuclei and prominent nucleoli (Figs. 4g-i). The syncytial cytoplasm acquired a homogenously red color in PASH sections (Fig. 4g). The outer envelope was not recognized at this stage. By the end of this stage, the epidermal epithelium became clearly distinguishable from the mesenchyme (Figs. 4h, i; Video S2). Muscle precursors began to differentiate underneath the epidermis (Fig. 6a).

\section{Stage 7}

The elongated embryo occupied the internal volume of the eggshell entirely, but no movement was observed in freshly isolated and cultivated eggs or by the classic oogram technique (Fig. S5). A small amount of dark yolk material was located in the poles of whole unstained eggs (Fig. 8d).
Eggs in this stage still correspond to Vogel and Prata's stage IV (Fig. 8). In histological sections, the unicellular lateral glands were highly stained in red by PASH and in green by Masson trichrome (Fig. 5a). They extended (gland ducts) towards the terebratorium. Their nuclei were smaller, irregularly round, and heterochromatic. The apical gland was formed by the fusion of three immature cells, positioned in the anterior region of the embryo and flanked by the two lateral glands (Fig. 5a). The apical gland was also stained in red by PASH and in green by Masson trichrome but exhibited a granular heterogeneous pattern (Fig. 5a). Three small irregularly shaped nuclei were located in the center of the apical gland. They were bigger than the lateral gland
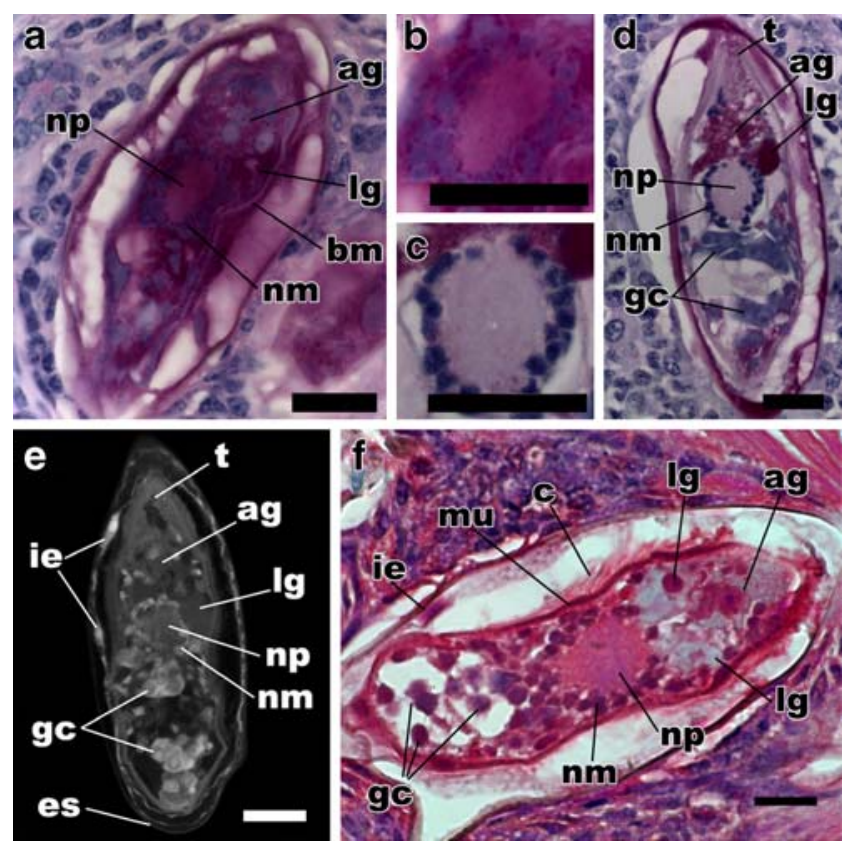

Fig. 5 Late organogenesis and mature $S$. mansoni eggs. a-d, f Bright field micrographs of eggs in the intestine of a host. a-d PASH staining. e Confocal laser scanning micrograph of a whole-mounted egg isolated from the murine host, stained with hydrochloric carmine. f Masson trichrome staining. a Stage 7. Parasagittal section of the embryo showing an almost complete embryonic development. The apical gland (ag) is completely fused and the lateral glands $(l g)$ are also formed. The basement membrane $(\mathrm{bm})$ is distinguishable by PASstained sections. Notice the morphology of neuronal nuclei magnified in b. They are bigger than in the stage 8 and present a lighter staining pattern. c-f Stage 8, mature egg. c Detail of the fully formed neural mass showed in d. Compare $\mathbf{b}$ and $\mathbf{c}$ to notice the nuclear condensation of neuronal nuclei and the increase of neuropile $(n p)$ size. The mature neural mass has smaller neuronal nuclei, with a stronger pattern of staining. d-f Parasagittal sections of the mature larvae, which is ready to hatch. It is possible to distinguish cilia (c), the subepidermal musculature $(m u)$, the inner envelope $(i e)$, the terebratorium $(t)$, the pair of lateral glands $(\lg )$, the apical gland $(a g)$, the mature neural mass $(\mathrm{nm})$ and its acellular neuropile $(\mathrm{np})$, and the germinal cells $(g c)$. The apical gland $(a g)$ presents a granular pattern of staining when compared with the lateral glands $(l g)$. In d, the PASpositive gland contents seem to be secreted to the interior of the egg in the murine host. Scale bars $20 \mu \mathrm{m}$ 
nuclei. The localization and staining pattern of both lateral and apical glands allowed the distinction between them (Fig. 5a). During this stage, the neural mass suffered nuclear condensation (Fig. 5a-f), giving rise to small roughly round or elongated nuclei. The process of neuronal nuclear condensation was followed by an increase in neuropile volume. The neurons had small nuclei, roughly round or elongated, and heterochromatic. In the midposterior pole of the embryo, germ cells showed the same aspect as in the previous stage. The eggshell was thicker in the poles, while the inner envelope kept its previous characteristics. The subepidermal musculature was revealed by Masson trichrome staining, and longitudinal and circular muscle fibers throughout the embryo were demonstrated by monoclonal antibody and phalloidin labeling (Fig. 6a-d).

\section{Stage 8}

Embryos occupied the whole interior of the egg. In freshly isolated and cultivated eggs or in the oogram (Figs. 8e and S5), they moved quickly, making circumvolutions inside the eggshell. Muscular contractions, cilia, and flame-cell beating were also indicative of maturity in live eggs. They were ready to hatch under appropriate conditions. This stage corresponds to the final stage V of Vogel and Prata's classification (Fig. 8). Even in unstained eggs, the central neural mass was easily recognized in the midanterior region of the miracidium (Fig. 8e). In sections, one to two layers of neurons were organized peripherally surrounding the roughly round neuropile (Fig. 5c-f; Video S3). The terebratorium, the apical gland, and both lateral glands were fully formed in the anterior region (Fig. 5d-f; Fig. S5c; Video S3). A marked change in positive reaction to PAS and PAS-AB staining occurred during the embryonic development of schistosome eggs (Fig. 7a-c). Morphological evidence of glandular secretions to the interior of the egg was observed inside the murine host (Fig. 5d). The epidermal surface was formed by ciliated epidermal plates,
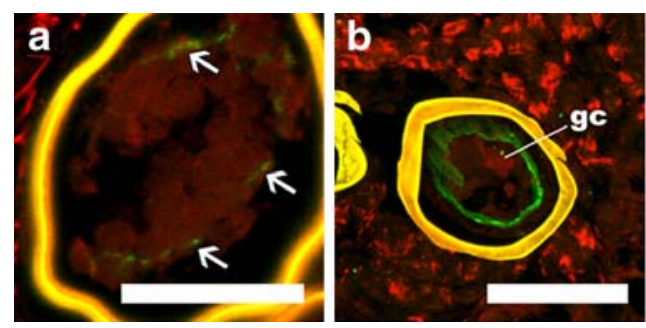

Fig. 6 Muscle differentiation in S. mansoni eggs. a-d Confocal laser scanning micrographs of eggs in the intestine of the host. a-c The monoclonal antibody reveals muscle fibers. Eggshell autofluorescence is seen in yellow. In a, muscle precursors (arrows) seem to differentiate underneath the epidermis in a probable stage 6 embryo. Scale bar $20 \mu \mathrm{m}$. b-c Projection of multiple virtual sections shows the organization of circular and longitudinal muscle fibers in two probable
Fig. 7 Patterns of PAS-positive reaction during $S$. mansoni egg embryogenesis. a-c Bright field microscopy micrographs of eggs in the intestine of a host, stained by PAS-AB method. a Eggs in stage 1 show positive weak reaction only in the yolk. No positive reaction stains the embryo (em) itself. b During the stage 4 , a light positive reaction stains the inner envelope (ie). The embryonic primordium (em) remains negative to PAS reaction. c Mature eggs (stage 8) are completely positive to PAS reaction, except in the neural mass $(\mathrm{nm})$ and in the basement membrane $(\mathrm{bm})$ that are lightly stained. It is possible to distinguish the neuronal nuclei and the neuropile $(n p)$ due to the negative staining of both structures. Scale bars $50 \mu \mathrm{m}$
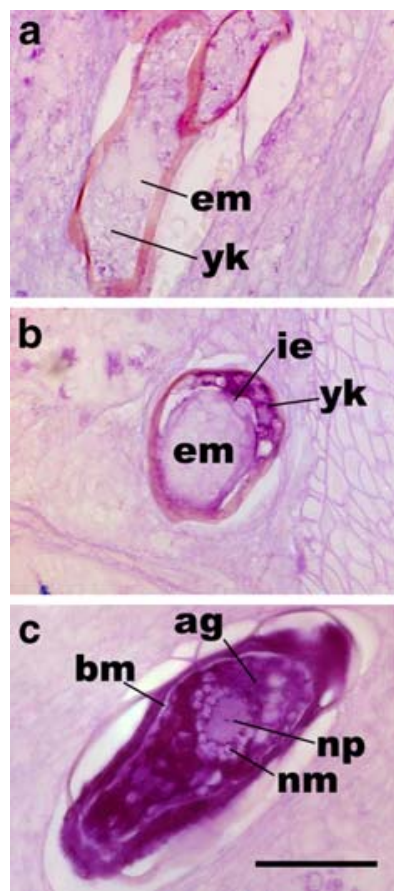

which produced a thin syncytium with round and basophilic nuclei. A conspicuous basal membrane separated the epidermal cells from the muscular adjacent layer, which was negatively revealed by PAS-AB (Fig. 7c). Flame cells were evidenced by phalloidin labeling but not by the monoclonal antibody (Fig. 6c, d). No mitotic figures were seen throughout the embryo. Germ cells were arranged in groups of three to five cells in the midposterior pole (Fig. 5d-f; Video S3). Considering the eggshell structures, the outer envelope kept its previous features, while the inner envelope seemed less thick (Fig. 5e, f; Video S3).

\section{Discussion}

The present investigation describes for the first time the sequence of the morphological events that occur during
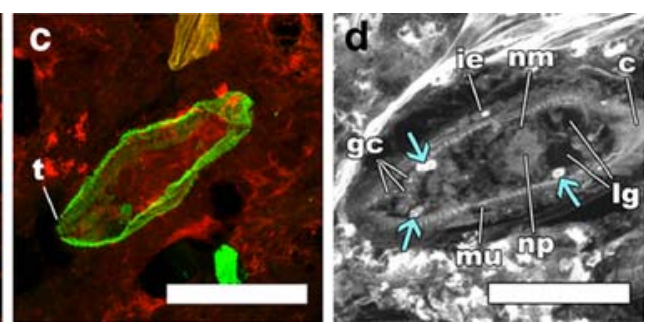

mature embryos. This antibody does not label the flame cells. The eggshell in c was presumably removed during the histological processing. d Parasagittal projection of multiple virtual sections of a mature embryo. Phalloidin labeling reveals both the musculature $(\mathrm{mu})$ and the flame cells (arrows). c, cilia; ie, inner envelope; $t$, terebratorium; $l g$, lateral glands; $n m$, neural mass; $n p$, neuropile; $g c$, germinal cells. Scale bars $50 \mu \mathrm{m}$ 
schistosome egg development up to the complete formation of the ciliated larva (miracidium; see Fig. 8). Our classification was based on a recently introduced morphological staging system and adapted to other flatworm species (Hartenstein and Ehlers 2000; Younossi-Hartenstein et al. 2000; Younossi-Hartenstein and Hartenstein 2000a, b, 2001; Ramachandra et al. 2002; Morris et al. 2004; Cardona et al. 2005, 2006). Egg maturation under in vivo and in vitro conditions has been also evaluated statistically by using the ratio of embryo to egg size as a simple characteristic and
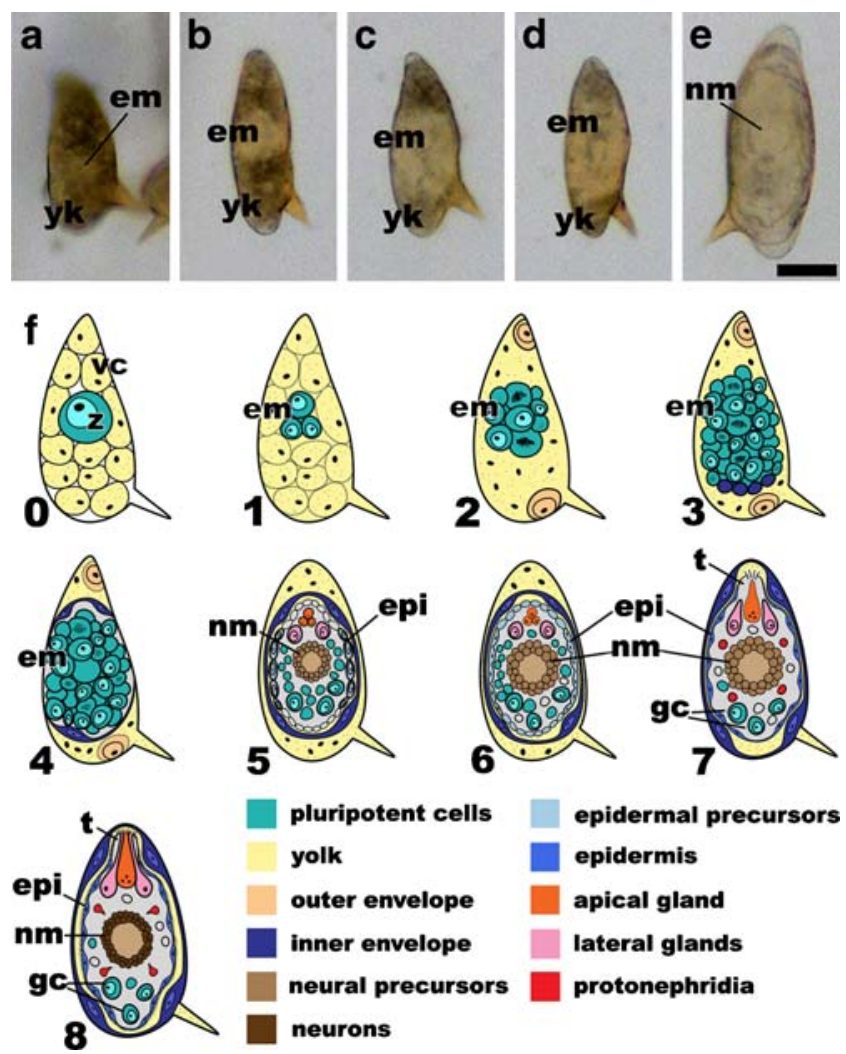

Fig. 8 Comparison between the staging systems of $S$. mansoni egg maturation. a-e Bright field micrographs of whole unstained eggs isolated from murine host, in accordance with Vogel and Prata's staging system. a Stage I. b Stage II. c Stage III. d Stage IV. e Stage V (mature egg). Notice the increase in embryo $(\mathrm{em})$ size in relation to egg size itself. Scale bar $20 \mu \mathrm{m}$. More details in the text. f Schematic drawings of the major events of egg embryogenesis in ventral view. Anterior is at the top and posterior at the bottom. The number at the bottom left of each drawing indicates the embryonic stage according to the morphological events, as defined in the text. Tissues are shaded in different colors as shown at the bottom right of the panel. Dotted lines indicate cell fusion. Cilia were not represented. They arise in late stage 7. Drawings are not in scale. For more information on the morphological events during embryogenesis, see the text. The zygotic stage (also stage 0) occurs inside the female worm. Stage 1 corresponds to Vogel and Prata's stage I. Stage 2 to Vogel and Prata's stage II and stages 3 and 4 to Vogel and Prata's stage III. Stages 5, 6, and 7 occur during Vogel and Prata's stage IV. Finally, the mature embryo in stage 8 corresponds to Vogel and Prata's stage V. $y k$, yolk; $v c$, vitelline cells; $n m$, neural mass; ie, inner envelope; $t$, terebratorium; $l g$, lateral glands; $g c$, germinal cells morphologically by staining whole eggs with carmine (see Jurberg et al. 2008b).

Schistosomes undergo the neoophoran mode of development, in which a specialized organ (vitellarium or vitelline gland) provides individualized vitelline cells that surround the zygote in the vitelline-oviduct before entering the eggshellforming apparatus (the ootype). The number of vitelline cells within the newly formed egg capsule of S. mansoni is not precise in the literature, varying from 20 to 40 cells (Gonnert 1955; Wells and Cordingley 1991; Swiderski 1994; Michel et al. 2003; Knobloch et al. 2006). Our preliminary findings on eggshell formation in whole-mount mature females analyzed by CLSM demonstrated approximately 40-45 individualized vitelline cells in each early formed egg, but additional analyses must be carried out to reach statistically significant data. In schistosomes, the vitelline cells are haploid, suggesting a common origin for the vitelline gland and the ovary (Basch and Samuelson 1990). Vitelline cells probably play a key role in eggshell formation and a reduced importance in embryo nourishment (Erasmus 1975; Erasmus et al. 1982; Bobek et al. 1986; Johnson et al. 1987; Koster et al. 1988; Reis et al. 1989; Chen et al. 1992; Schussler et al. 1995; Fitzpatrick et al. 2004, 2007). The eggshell has cribriform-like pores, which allow the uptake of exogenous nutrients during egg migration through host tissues (Lewert et al. 1970; Stjernholm and Warren 1974; Neill et al. 1988; Swiderski 1994). As noted by several authors and confirmed by our findings, schistosome eggs are not retained in the female parental uterus and remain undeveloped when laid.

Before studying egg embryogenesis, the morphology of the miracidium was analyzed by histology and wholemount preparations to define "hallmark" structures for each stage of embryo formation. Previously, the morphology of the fully formed and newly hatched larva of S. mansoni was extensively studied by two authors using BM (Ottolina 1957) and transmission electron microscopy (TEM; Pan 1980). Our findings on the schistosome miracidium morphology are in agreement with Pan (1980). Unlike Hartenstein and Ehlers (2000) for the rhabdocoel M. lingua, such distinctive structures were difficult to recognize in mature unhatched larva, even under differential interference contrast microscopy (data not shown). Muscle contraction, cilia, and flame-cell beating are easily observed in mature eggs, indicating miracidium viability (Prata 1957). Flamecell differentiation seems to occur late during organogenesis (perhaps starting at stage 7), but additional investigations are still needed to clarify its emergence. Bahia et al. (2006) have recently revealed the distribution of motor proteins in the musculature and flame cells of miracidia and primary sporocysts.

An attempt to improve embryo visualization by removing the eggshell from isolated eggs was not successful in the present work (data not shown). To circumvent this 
drawback, we employed a previously adapted staining protocol for single whole eggs for confocal microscopy (Jurberg et al. 2008b). This work also shows that it is possible to apply the same staining in conjunction with the oogram technique (Fig. S5). The classical technique by Pellegrino et al. (1962) is commonly used to infer interruption of egg laying on chemotherapeutic evaluations, which causes changes of egg frequencies in host tissues (in this case, intestine). However, this technique does not assess the effect of drug treatment on the egg embryonic development. The oogram technique in conjunction with carmine staining and CLSM allowed us to note in great detail the morphological events during egg embryogenesis in situ (Fig. S5). It is important to emphasize the need to compress very well the intestinal samples during preparation. The analyses of whole eggs from in vivo and in vitro conditions could bring additional information on egg biology, especially seeking phenotypic changes caused by drugs or, for instance, in RNA interference-mediated knockdown studies, as performed by Freitas et al. (2007). Removal of the eggshell will certainly improve embryo visualization, facilitating embryonic cell lineage tracing, TEM, and immunolabeling procedures.

Although the described morphogenetic events in live eggs are difficult to be seen, it is possible to correlate them with Vogel and Prata's staging system (Vogel 1942; Prata 1957; Fig. 8). The events that take place inside the female were also considered. They were divided in two stages. The first stage refers to the prezygotic stage where the mature oocyte is released from the multilobated ovary until its fecundation in the short segment of the oviduct, just before the seminal receptacle. The zygotic stage (also stage 0 ) is limited to the period of migration inside the female genital tract until the egg discharge through the gonopore. It comprises a cluster of cells (zygote plus vitelline cells) in the vitelline-oviduct, followed by the eggshell formation in the ootype and the formed egg in the uterus. Early cleavages correspond both to our stage 1 and Vogel and Prata's stage I, in which the embryonic primordium is too small to be visible under BM. At the end of this stage, the embryo becomes visible as a clear central disk, occupying one third of the diameter of the egg. Our stage 2 corresponds to late cleavages, in which the embryonic mass becomes bigger (stereoblastula), occupying one half of the egg diameter. This is equivalent to Vogel and Prata's stage II. When the embryo elongates and occupies two thirds of the length of the egg, it is classified as Vogel and Prata's stage III. This stage was divided by us into two novel stages: stage 3, when cellular differentiation starts producing at least two cell types, in addition to stage 4 , where the first embryonic primordium (central neural mass) arises from a mesenchymal mass of cells. At Vogel and Prata's stage IV, the embryo increases in size occupying almost the entire egg. This stage represents the main steps of organogenesis and can be also divided: our stage 5 refers to the beginning of epidermis formation; and our stage 6 , where terebratorium and miracidial glands differentiations take place; in addition to stage 7 , where the neural mass suffers nuclear condensation. In both staging systems, the last stage (Vogel and Prata's stage V and our stage 8) refers to the fully formed larva before hatching (Fig. 8).

The development of eggs laid in vitro and of eggs isolated from the murine host was compared by statistics (using only Vogel and Prata's staging system; see Supplementary results) and morphological analysis of whole-mount eggs at different stages of maturation (using both staging systems). Despite the lack of information on its embryonic development, schistosome eggs have been commonly maintained under culture conditions for a wide variety of purposes, such as drug screening, antibody production, and RNA interference knockdown (Asahi and Stadecker 2003; Schramm et al. 2006; Freitas et al. 2007; de Araujo et al. 2007; Cass et al. 2007). However, as stressed by Gobert et al. (2007), caution is required when considering the use of in vitro parasites for molecular or biochemical levels. Michaels and Prata (1968) have followed egg maturation in two distinct culture media and defined the M199 containing 10\% calf serum as more adequate to support egg embryogenesis and miracidial life span as well as the host environment. However, other authors prefer the RPMI-1640 culture medium (Ashton et al. 2001; Kusel et al. 2006; Schramm et al. 2006). We have evaluated here the embryonic development of S. mansoni eggs in this medium and compared it with data obtained from isolated eggs. With the conditions used here, undeveloped eggs laid in vitro were able to reach maturity and hatch when placed in water. The fully formed larva also infects Biomphalaria glabrata snails, with cercaria release (data not shown). In both environments (culture and host), eggs significantly increased in size during development (Table S2; Fig. S4), which was previously reported on eggs obtained from the host by Prata (1957) and on cultivated eggs by Michaels and Prata (1968). Ashton et al. (2001) confirmed this growth by calculating a factor of biomass gain in 3.33. Egg growth among platyhelminths is uncommon and its biological significance is still obscure. The statistically significant differences between the mean estimated areas of cultivated and isolated eggs at distinct stages of maturation may suggest unequal rates of maturation since the gross morphology of each matching stage seems to be similar. Moreover, no significant differences were detected when the area of mature eggs from both environments was compared. Thus, eggs obtained under culture could be employed for morphological studies on the embryogenesis of $S$. mansoni, although biochemical and molecular data should be considered with wariness, as discussed by Gobert et al. (2007) for schistosomula. A main difference in cultivated eggs refers to the lack of 
evident signs of death when compared with eggs from the host (Michaels and Prata 1968). Sarvel et al. (2006) used the fluorescent probe Hoechst 33258 to differentiate dead eggs from live ones by labeling nuclei of damaged cells. This approach failed to work when performed in conjunction to carmine staining, even modifying the order of the staining steps (data not shown).

As seen in culture conditions, eggs within the female reproductive system did not undergo any cleavage and the first mitotic division occurred only in the female external environment (host bloodstream or culture). The mitogenic triggering signal(s) to embryo cells remains unknown. Before the first total unequal cleavage, vitelline cells start to fuse progressively into a single syncytium, as also reported by Swiderski (1994). Cell fusion is a key process for plant and animal development and is quite common during miracidium embryogenesis (in the formation of inner and outer envelopes, apical gland, and epidermis). Several other examples are available in the literature (Podbilewicz 2006; Oren-Suissa and Podbilewicz 2007; Larsson et al. 2008). Generally, the close approach of two lipid bilayers is required and then followed by the formation of a fusion pore and cytoplasmic mixing to form a syncytium (Oren-Suissa and Podbilewicz 2007). However, the mechanism of vitelline fusion during the embryonic development of schistosome eggs is unknown. It is possible that yolk syncytium formation facilitates nutrient availability to the embryo, including the uptake of host metabolites via eggshell pores (Lewert et al. 1970; Stjernholm and Warren 1974). Remnants of the vitelline cells also fused with two macromeres that have detached from the poles of the developing stereoblastula and adhered to the internal surface of eggshell to form the outer envelope, as also reported by Swiderski (1994). This started to occur in the period here classified as stage 2 (late cleavage) and disappears progressively around stage 4 (organ primordia formation). Ultrastructurally, the outer envelope thickened as maturation proceeded, especially at the poles of the eggshell. Later stages were characterized by an acellular matte of arborizing and anastomosing electron-dense fibrils in a finely granular matrix with many free ribosomes in mature eggs (Neill et al. 1988; Swiderski 1994). On the other hand, the egg inner envelope arose exclusively from peripheral embryonic cells that started to differentiate at our stage 3. Nevertheless, it became apparent in the following stage 4, while fusion proceeded to encircle the embryo as a detaching syncytial layer slightly positive to PAS. During these later stages, the inner envelope expands while embryos grew and adhered to the remnants of the outer envelope. Nuclei were flattened and large, with scant heterochromatin and prominent nucleoli, while the cytoplasm was thin, with developed granular reticulum, abundant polysomes, elongated mitochondria, and several lipid droplets. In mature eggs, this envelope deteriorates (Neill et al. 1988; Swiderski 1994;
Ashton et al. 2001), which may facilitate the release of egg antigens to the surrounding environment.

The marked changes observed in the PAS and PAS-AB methods during egg maturation revealed the production of neutral glycoproteins, first by the inner envelope (beginning in stage 4) and then by miracidial glands (in stage 6). Mature embryos secrete large amounts of neutral glycoproteins, strongly positive to the PAS reaction. This may explain why granuloma formation occurs only around single mature eggs but not around immature ones (Prata 1957). Indeed, Andrade and Barka (1962) first suggested that host immunogenic antigens are polysaccharides or glycoproteins. It is now known that schistosome eggs secrete at least 188 proteins of a wide variety of functions (Cass et al. 2007) and that granulomatogenic activity is triggered specifically by glycoconjugates with terminal Galß1-4GlcNAc (LacNAc) or LacdiNAC elements (Van de Vijver et al. 2006). The localization of these eggsecreted total proteins was attributed to egg envelopes instead of the miracidium itself (Ashton et al. 2001). However, as first pointed out by Lewert and Lee (1954), miracidial glands are also positive to the PAS reaction. Our results showed that both types of miracidial glands (lateral and apical) differentiated late in development (stages 6 and 7), producing PAS-positive granules which were secreted to the interior of the egg in the fully formed miracidium. Then, together with egg envelopes (Ashton et al. 2001; Schramm et al. 2006; Van de Vijver et al. 2006), it is possible that the gland material also contributes to granuloma formation. Besides the production of immunogenic components, egg envelopes may play another important role, acting as a slow antigen-releasing barrier to the surrounding environment and preventing premature egg expulsion to the gut lumen (Ashton et al. 2001). The differentiation of miracidial glands also strengthens this scenario since their glycoprotein production started late during egg development. Further histochemical (lectins) and immunohistochemical studies should be performed to evaluate the role of specific egg antigens during embryo formation and to clarify the role of miracidial glands during granulomatogenesis. Thus far, only a few egg antigens have been located exclusively in mature eggs (e.g., Williams et al. 2001; Schramm et al. 2006; Van de Vijver et al. 2006).

Apoptosis in platyhelminths was first reported in the free-living Macrostomum sp. (Nimeth et al. 2002) and then observed in planarians during regeneration (Hwang et al. 2004). Nuclear morphology assessed by Giemsa staining is considered a reliable criterion for apoptosis determination (e.g., see Baskic et al. 2006). In schistosome egg embryogenesis, signs of programmed cell death as pycnotic nuclei were found during late cleavage, the blastula stage, and early organogenesis. Presumably, cell death is involved in tissue formation and arrangement. However, its role in 
tissue homeostasis during embryonic development of schistosome eggs remains to be better evaluated in further studies.

Following formation of the envelopes, organogenesis started to occur (beginning in stage 5). Phylogenetically, schistosome egg development was quite similar to the rhabdocoel pattern showed by $M$. lingua, in which gastrulation does not occur (see Hartenstein and Ehlers 2000). The cleavage-resulting solid blastula gives rise to organ primordia, such as the neural mass ("brain"), the epidermis, and other organs from mesenchymal cells, but unlike rhabdocoels, schistosome embryos do not form pharynx and gut during egg development. The lack of such structures is probably associated with the parasitic lifestyle. They will appear only during miracidium-sporocystcercariae transformation within the snail intermediate host (Andrade and Sadigursky 1978; Pan 1996; Dorsey et al. 2002). Another similar event is the formation of egg embryonic envelopes, which might be derivatives of the huell membrane of turbellarian flatworms. For instance, in Mesostoma, this transient membrane arises from vitelline cells that surround the embryo ventrally and disappears progressively around stage 6 (Hartenstein and Ehlers 2000). However, as other parasitic platyhelminths (e.g., cestodes), schistosomes have two envelopes, which may demonstrate adaptation to parasitism. They protect the developing and fully formed miracidium, acting as nutrient-producing and storage compartments, secreting immunogenic materials which can contribute to egg expulsion to gut lumen, and providing motility for miracidial movements prior to hatching (Neill et al. 1988; Swiderski 1994; Ashton et al. 2001; see also Conn and Swiderski 2008). Both envelopes are cellular in origin and syncytial in nature and enclose the embryo (Swiderski 1994). Nevertheless, the outer envelope has mixed origin (from macromeres and vitelline cells) and disappears gradually (such as the huell membrane), while the inner envelope arises from mesomeres and persists until egg hatching.

Epidermis formation began during stage 5 by fusion of an embryonic peripheral monolayer, just underneath the inner envelope. As differentiation proceeded, single epidermal cells form hundreds of cilia that became identifiable by BM and CLSM around stage 7. However, it is possible that their formation start a little earlier and further ultrastructural studies on the developing body wall are required. The body wall of S. mansoni miracidia is arranged in four tiers of six, eight, four, and three plates, from the anterior to the posterior end (Pan 1980; Eklu-Natey et al. 1985). These plates are separated from each other by epidermal ridges, interconnected by their cell bodies and narrow cytoplasmic bridges, except in the first tier where no ridges separate them (Pan 1980; Eklu-Natey et al. 1985). As noted by Pan (1980, 1996), the terebratorium appears to be a modified epidermal ridge, which contains at least 12 peripheral sensory organelles and the openings of miracidial gland ducts. In S. mansoni, it has a "honeycomb" pattern (Eklu-Natey et al. 1985). The underlying muscle layer was visible in mature embryos, but its differentiation should be detailed by immunohistochemical and ultrastructural studies. Epidermis formation, cilia growth, and terebratorium differentiation should also be detailed by TEM and scanning electron microscopy in further studies. Parasitic platyhelminths belong to the monophyletic group Neodermata (Ehlers 1985; Littlewood et al. 1999), in which the larval ciliated epidermis is replaced by a syncytial nonciliated epidermis with "insunk" nuclei (tegument) in the adult, called neodermis (Tyler and Tyler 1997).

In late stages of miracidium embryogenesis, when the larva was almost fully formed, germ cells were evident in whole-mounts or histological sections but were not considered as a reference feature due to their similarity with early immature cells (blastomeres). They possess large round nuclei, prominent nucleoli, and scarce cytoplasm. Based on ultrastructural observations of the miracidium-sporocyst transformation in the snail host (Pan 1996), we postulate that the miracidial germ cells may be homologous to neoblasts of other platyhelminth worms, although no accounts of regeneration potential have been given for any of schistosomal evolutive stages. Both cell types have remarkable proliferative capacity and are morphologically defined by a prominent nucleus and a small rim of basophilic cytoplasm and by free ribosomes and a relatively small amount or lack of endoplasmic reticulum. Miracidial germ cells have many mitochondria unlike well-established neoblasts (Pan 1980; Gschwentner et al. 2001).

The staging system introduced by the Hartenstein group for free-living flatworms (Hartenstein and Ehlers 2000) was very useful to detail and classify schistosome egg embryogenesis. The assumption considered by Younossi-Hartenstein and Hartenstein (2001) that the temporal sequence in which homologous morphogenetic events occur, and the spatial framework in which these events unfold, is sufficiently similar between some flatworms is also valid for the trematode parasite $S$. mansoni. However, miracidia of schistosomes do not have primitive gut and eyespots (for S. mansoni, see Pan 1980). Unfortunately, it was not possible to define the initial and intermediate ontogenetic steps of the excretory system.

In conclusion, we propose here a new staging system for S. mansoni egg maturation, in which two pre-embryonic stages occur inside the female worm and then eight embryonic stages take place after egg laying. Stage 1 refers to early cleavages and the beginning of yolk fusion. Stage 2 represents late cleavage, with the formation of a stereoblastula and the onset of outer envelope differentiation. Stage 3 is defined by the elongation of the embryonic 
primordium and the onset of inner envelope formation. In stage 4, the first organ primordia arise. During stages 5-7, tissue and organ differentiation occur (neural mass, epidermis, terebratorium, musculature, and miracidial glands). Stage 7 is characterized by nuclear condensation of neural mass neurons. Stage 8 refers to the fully formed larva, presenting muscular contraction, cilia, and flame-cell beating. However, since these morphological events are difficult to visualize in live eggs, our classification should be considered simultaneously with Vogel and Prata's staging system whenever convenient. In the future, the staging system proposed here could contribute to a better comprehension of $S$. mansoni egg biology, by the generation of cell lineage fate maps and the localization of molecular components (as granuloma-triggering antigens) during embryogenesis ("egg localizome").

Acknowledgments The authors acknowledge the staff of the Laboratório de Patologia-IOC/Fiocruz and of the Laboratório de Esquistossomose-CPqRR/Fiocruz for technical assistance, Mr. Bruno Eschenazi from the Setor de Produção e Tratamento de Imagens-IOC/ Fiocruz for the schematic drawing of $S$. mansoni egg embryonic development, Dr. Jane Arnt Lenzi from the Laboratório de PatologiaIOC/Fiocruz and Dr. John R Kusel from the Glasgow University for critical review of the manuscript, and Dr. Jennifer Rowland from the Laboratory of Patterning and Morphogenesis-Instituto Gulbenkian de Ciência for the English review. ADJ and TG received fellowships from the Conselho Nacional de Desenvolvimento Científico e Tecnológico (CNPq) - Brazil. TAC and ACA de M received fellowships from the Coordenação de Aperfeiçoamento de Pessoal de Nível Superior (CAPES)-Brazil. The work was supported by the Fundação Oswaldo Cruz (Fiocruz).

\section{References}

Andrade ZA, Barka T (1962) Histochemical observations on experimental schistosomiasis of mouse. Am J Trop Med Hyg 11:12-16

Andrade ZA, Sadigursky M (1978) Immunofluorescence studies of schistosome structures which share determinants with circulating schistosome antigens. Trans R Soc Trop Med Hyg 72:316-317

Asahi H, Stadecker MJ (2003) Analysis of egg antigens inducing hepatic lesions in schistosome infection. Parasitol Int 52:361-367

Ashton PD, Harrop R, Shah B, Wilson RA (2001) The schistosome egg: development and secretions. Parasitology 122:329-338

Bahia D, Avelar LGA, Vigorosi F, Cioli D, Oliveira GC, Mortara RA (2006) The distribution of motor proteins in the muscles and flame cells of the Schistosoma mansoni miracidium and primary sporocyst. Parasitology 133:321-329

Bancroft JD, Stevens A (1996) Theory and practice of histological techniques, 4th edn. Churchill Livingstone, New York

Basch PF, Samuelson J (1990) Cell biology of schistosomes. I. Ultrastructure and transformations. In: Wyler DJ (ed) Modern parasite biology: cellular, immunological, and molecular aspects. Freeman, New York, pp 91-106

Baskic D, Popovic S, Ristic P, Arsenijevic NN (2006) Analysis of cycloheximide-induced apoptosis in human leukocytes: fluorescence microscopy using annexin V/propidium iodide versus acridin orange/ethidium bromide. Cell Biol Int 30:924-932
Bobek L, Rekosh DM, van Keulen H, LoVerde PT (1986) Characterization of a female-specific cDNA derived from a developmentally regulated mRNA in the human blood fluke Schistosoma mansoni. Proc Natl Acad Sci U S A 83:5544-5548

Cardona A, Hartenstein V, Romero R (2005) The embryonic development of the triclad Schmidtea polychroa. Dev Genes Evol 215:109-131

Cardona A, Hartenstein V, Romero R (2006) Early embryogenesis of planaria: a cryptic larva feeding on maternal resources. Dev Genes Evol 216:667-681

Carson FL, Martin JH, Lynn JA (1973) Formalin fixation for electron microscopy: a re-evaluation. Am J Clin Pathol 59:365-373

Cass CL, Johnson JR, Califf LL, Xu T, Hernandez HJ, Stadecker MJ, Yates JR 3rd, Williams DL (2007) Proteomic analysis of Schistosoma mansoni egg secretions. Mol Biochem Parasitol 155:84-93

Chen LL, Rekosh DM, LoVerde PT (1992) Schistosoma mansoni p48 eggshell protein gene: characterization, developmentally regulated expression and comparison to the p14 eggshell protein gene. Mol Biochem Parasitol 52:39-52

Chernin E (1970) Behavioral responses of miracidia of Schistosoma mansoni and other trematodes to substances emitted by snails. J Parasitol 56:287-296

Chernin E (1974) Some host-finding attributes of Schistosoma mansoni miracidia. Am J Trop Med Hyg 23:320-327

Chitsulo L, Engels D, Montresor A, Savioli L (2000) The global status of schistosomiasis and its control. Acta Trop 77:41-51

Coelho MV (1957) Aspectos do desenvolvimento de formas larvárias de Schistosoma mansoni em Australorbis nigricans. Rev Bras Biol 17:325-337

Coelho PMZ, Andrade ZA, Borges C, Ribeiro F, Barbosa L (2008) Evolução do Schistosoma mansoni no Hospedeiro Intermediário. In: Carvalho ODS, Coelho PMZ, Lenzi HL (eds) Schistosoma mansoni e Esquistossomose: uma visão multidisciplinar. Fiocruz, Rio de Janeiro, pp 147-160

Conn DB, Swiderski Z (2008) A standardised terminology of the embryonic envelopes and associated developmental stages of tapeworms (Platyhelminthes: Cestoda). Folia Parasitol (Praha) 55:42-52

Cunha AS, Pellegrino J, Oliveira CA, Alvarenga RJ (1962) Observations on the oogram in guinea pigs and rabbits experimentally infected with Schistosoma mansoni. Rev Inst Med Trop Sao Paulo 4:242-248

Dalton JP, Day SR, Drew AC, Brindley PJ (1997) A method for the isolation of schistosome eggs and miracidia free of contaminating host tissues. Parasitology 115(Pt 1):29-32

de Araujo SC, de Mattos AC, Teixeira HF, Coelho PM, Nelson DL, de Oliveira MC (2007) Improvement of in vitro efficacy of a novel schistosomicidal drug by incorporation into nanoemulsions. Int $\mathrm{J}$ Pharm 337:307-315

R Development Core Team (2008) R: a language and environment for statistical computing. R Foundation for Statistical Computing, Vienna. http://www.R-project.org. Accessed 7 Feb 2009

Dorsey CH, Cousin CE, Lewis FA, Stirewalt MA (2002) Ultrastructure of the Schistosoma mansoni cercaria. Micron 33:279-323

Dresden MH, Payne DC (1981) A sieving method for the collection of schistosome eggs from mouse intestines. J Parasitol 67:450-452

Ehlers U (1985) Das phylogenetische System der Plathelminthes. Fischer, Stuttgart

Eklu-Natey DT, Wuest J, Swiderski Z, Striebel HP, Huggel H (1985) Comparative scanning electron microscope (SEM) study of miracidia of four human schistosome species. Int $\mathrm{J}$ Parasitol $15: 33-42$

Erasmus DA (1975) The subcellular localization of labelled tyrosine in the vitelline cells of Schistosoma mansoni. Z Parasitenkd 46:75-81 
Erasmus DA, Popiel I, Shaw JR (1982) A comparative study of the vitelline cell in Schistosoma mansoni, S. haematobium, S. japonicum and $S$. mattheei. Parasitology 84:283-287

Espin J (1941) La sustancia meplasmática en los nódulos producidos por Schistosoma mansoni. Rev Pol Caracas 10:73-90

Fitzpatrick JM, Johansen MV, Johnston DA, Dunne DW, Hoffmann KF (2004) Gender-associated gene expression in two related strains of Schistosoma japonicum. Mol Biochem Parasitol 136:191-209

Fitzpatrick JM, Hirai Y, Hirai H, Hoffmann KF (2007) Schistosome egg production is dependent upon the activities of two developmentally regulated tyrosinases. FASEB J 21:823-835

Freitas TC, Jung E, Pearce EJ (2007) TGF-beta signaling controls embryo development in the parasitic flatworm Schistosoma mansoni. PLoS Pathog 3:e52

Gobert GN, Chai M, McManus DP (2007) Biology of the schistosome lung-stage schistosomulum. Parasitology 134:453-460

Gonçalves T (2008) Correlação entre a difusão de material antigênico de ovo de Schistosoma mansoni com a expressão de moléculas de adesão de complexos juncionais em granulomas hepáticos murinos. Master's Dissertation, Instituto Oswaldo Cruz, Fundação Oswaldo Cruz, Rio de Janeiro

Gonnert R (1955) Schistosomiasis-Studien, 1 Beitrage zur Anatomie und Histologie von Schistosoma mansoni. Z Tropenmed Parasitol 6:18-33

Gschwentner R, Ladurner P, Nimeth K, Rieger R (2001) Stem cells in a basal bilaterian. S-phase and mitotic cells in Convolutriloba longifissura (Acoela, Platyhelminthes). Cell Tissue Res 304:401408

Haas W, Haberl B, Schmalfuss G, Khayyal MT (1994) Schistosoma haematobium cercarial host-finding and host-recognition differs from that of S. mansoni. J Parasitol 80:345-353

Haberl B, Kalbe M, Fuchs H, Ströbel M, Schmalfuss G, Haas W (1995) Schistosoma mansoni and S. haematobium: miracidial host-finding behaviour is stimulated by macromolecules. Int $\mathrm{J}$ Parasitol 25:551-560

Hartenstein V, Ehlers U (2000) The embryonic development of the rhabdocoel flatworm Mesostoma lingua (Abildgaard, 1789). Dev Genes Evol 210:399-415

Hartenstein V, Jones M (2003) The embryonic development of the body wall and nervous system of the cestode flatworm Hymenolepis diminuta. Cell Tissue Res 311:427-435

Hwang JS, Kobayashi C, Agata K, Ikeo K, Gojobori T (2004) Detection of apoptosis during planarian regeneration by the expression of apoptosis-related genes and TUNEL assay. Gene 333:15-25

Johnson KS, Taylor DW, Cordingley JS (1987) Possible eggshell protein gene from Schistosoma mansoni. Mol Biochem Parasitol 22:89-100

Jurberg AD, Oliveira AA, Lenzi HL, Coelho PM (2008a) A new miracidia hatching device for diagnosing schistosomiasis. Mem Inst Oswaldo Cruz 103:112-114

Jurberg AD, Pascarelli BM, Pelajo-Machado M, Maldonado A Jr, Mota EM, Lenzi HL (2008b) Trematode embryology: a new method for whole-egg analysis by confocal microscopy. Dev Genes Evol 218:267-271

Knobloch J, Kunz W, Grevelding CG (2006) Herbimycin A suppresses mitotic activity and egg production of female Schistosoma mansoni. Int J Parasitol 36:1261-1272

Koster B, Dargatz H, Schroder J, Hirzmann J, Haarmann C, Symmons P, Kunz W (1988) Identification and localisation of the products of a putative eggshell precursor gene in the vitellarium of Schistosoma mansoni. Mol Biochem Parasitol 31:183-198

Kusel JR, Oliveira FA, Todd M, Ronketti F, Lima SF, Mattos AC, Reis KT, Coelho PM, Thornhill JA, Ribeiro F (2006) The effects of drugs, ions, and poly-1-lysine on the excretory system of Schistosoma mansoni. Mem Inst Oswaldo Cruz 101(Suppl 1):293-298

Larsson LI, Bjerregaard B, Talts JF (2008) Cell fusions in mammals. Histochem Cell Biol 129:551-561

Lennert K (1978) Malignant lymphomas other than Hodgkin's disease. Springer, Berlin

Lenzi HL, Lenzi JA, Sobral AC (1987) Eosinophils favor the passage of eggs to the intestinal lumen in schistosomiasis. Br J Med Biol Res 20:433-435

Lenzi HL, Lenzi JA, Kerr IB, Antunes SL, Mota EM, Oliveira DN (1991) Extracellular matrix in parasitic and infectious diseases. Mem Inst Oswaldo Cruz 86:77-90

Lenzi HL, Jurberg AD, Coelho PMZ, Lenzi JA (2008) Migração e Desenvolvimento do Schistosoma mansoni no Hospedeiro Definitivo. In: Carvalho ODS, Coelho PMZ, Lenzi HL (eds) Schistosoma mansoni e Esquistossomose: uma visão multidisciplinar. Fiocruz, Rio de Janeiro, pp 85-145

Lewert RM, Lee CL (1954) Studies on the passage of helminth larvae through host tissues. I. Histochemical studies on the extracellular changes caused by penetrating larvae. II. Enzymatic activity of larvae in vitro and in vivo. J Infect Dis 95:13-51

Lewert RM, Para J, Ozcel MA (1970) Miracidial uptake of glucose in intact eggs of Schistosoma mansoni. J Parasitol 56:1250-1251

Lillie RD, Fullmer HM (1976) Histopathological technique and practical histochemistry. McGraw Hill, New York

Littlewood DTJ, Rohde K, Bray RA, Herniou EA (1999) Phylogeny of the Platyhelminthes and the evolution of parasitism. Biol J Linn Soc Lond 68:257-287

Machado-Silva JR, Pelajo-Machado M, Lenzi HL, Gomes DC (1998) Morphological study of adult male worms of Schistosoma mansoni Sambon, 1907 by confocal laser scanning microscopy. Mem Inst Oswaldo Cruz 93(Suppl 1):303-307

Maldonado JF, Acosta-Matienzo J (1947) Evolution del Schistosoma mansoni dentro de su hosped intermediário, el caracol Australorbis glabratus. P R J Public Health Trop Med 22:374-404

McLaren DJ (1980) Schistosoma mansoni: the parasite surface in relation to host immunity. Research Studies, New York

Michaels RM, Prata A (1968) Evolution and characteristics of Schistosoma mansoni eggs laid in vitro. J Parasitol 54:921-930

Michel A, Knobloch J, Kunz W (2003) P19: a female and tissue specifically expressed gene in Schistosoma mansoni, regulated by pairing with the male. Parasitology 127:519-524

Moore DV, Sandground JH (1956) The relative egg producing capacity of Schistosoma mansoni and Schistosoma japonicum. Am J Trop Med Hyg 5:831-840

Morris J, Nallur R, Ladurner P, Egger B, Rieger R, Hartenstein V (2004) The embryonic development of the flatworm Macrostomum sp. Dev Genes Evol 214:220-239

Neill PJ, Smith JH, Doughty BL, Kemp M (1988) The ultrastructure of the Schistosoma mansoni egg. Am J Trop Med Hyg 39:52-65

Neves RH, de Lamare Biolchini C, Machado-Silva JR, Carvalho JJ, Branquinho TB, Lenzi HL, Hulstijn M, Gomes DC (2005) A new description of the reproductive system of Schistosoma mansoni (Trematoda: Schistosomatidae) analyzed by confocal laser scanning microscopy. Parasitol Res 95:43-49

Nimeth K, Ladurner P, Gschwentner R, Salvenmoser W, Rieger R (2002) Cell renewal and apoptosis in Macrostomum sp. [Lignano]. Cell Biol Int 26:801-815

Oren-Suissa M, Podbilewicz B (2007) Cell fusion during development. Trends Cell Biol 17:537-546

Ottolina C (1957) El miracidio del Schistosoma mansoni: anatomía, citología, fisiología. Rev Sanid Asist Soc 22:1-412 discussion 413-420

Pan SC (1980) The fine structure of the miracidium of Schistosoma mansoni. J Invertebr Pathol 36:307-372 
Pan SC (1996) Schistosoma mansoni: the ultrastructure of larval morphogenesis in Biomphalaria glabrata and of associated hostparasite interactions. Jpn J Med Sci Biol 49:129-149

Pellegrino J, Coelho PM (1978) Schistosoma mansoni: wandering capacity of a worm couple. J Parasitol 64:181-182

Pellegrino J, Faria J (1965) The oogram method for the screening of drugs in schistosomiasis mansoni. Am J Trop Med Hyg 14:363-369

Pellegrino J, Oliveira CA, Faria J, Cunha AS (1962) New approach to the screening of drugs in experimental schistosomiasis mansoni in mice. Am J Trop Med Hyg 11:201-215

Peralta JM (1986) Obtenção e caracterização de anticorpos monoclonais para antígenos de Schistosoma mansoni. Ph.D. Thesis, Instituto de Microbiologia, Universidade Federal do Rio de Janeiro-UFRJ, Rio de Janeiro

Podbilewicz B (2006) Cell fusion. WormBook, pp 1-32

Prata A (1957) Biópsia retal na esquistossomose mansoni — bases e aplicações no diagnóstico e tratamento. Serviço Nacional de Educação Sanitária-Ministério da Saúde, Rio de Janeiro

Ramachandra NB, Gates RD, Ladurner P, Jacobs DK, Hartenstein V (2002) Embryonic development in the primitive bilaterian Neochildia fusca: normal morphogenesis and isolation of POU genes Brn-1 and Brn-3. Dev Genes Evol 212:55-69

Reis MG, Kuhns J, Blanton R, Davis AH (1989) Localization and pattern of expression of a female specific mRNA in Schistosoma mansoni. Mol Biochem Parasitol 32:113-119

Saladin KS (1982) Schistosoma mansoni: cercarial responses to irradiance changes. J Parasitol 68:120-124

Sarvel AK, Kusel JR, Araujo N, Coelho P, Katz N (2006) Comparison between morphological and staining characteristics of live and dead eggs of Schistosoma mansoni. Mem Inst Oswaldo Cruz 101 (Suppl 1):289-292

Schramm G, Gronow A, Knobloch J, Wippersteg V, Grevelding CG, Galle J, Fuller H, Stanley RG, Chiodini PL, Haas H, Doenhoff MJ (2006) IPSE/alpha-1: a major immunogenic component secreted from Schistosoma mansoni eggs. Mol Biochem Parasitol 147:9-19

Schussler P, Potters E, Winnen R, Bottke W, Kunz W (1995) An isoform of ferritin as a component of protein yolk platelets in Schistosoma mansoni. Mol Reprod Dev 41:325-330

Sorour F (1929) Contribution a l'etude des tumeurs irratitives bénignes et malignes produites par les Bilharzies. Ann Parasit 7:381-398

Stirewalt MA (1974) Schistosoma mansoni: cercaria to schistosomule. Adv Parasitol 12:115-182
Stjernholm RL, Warren KS (1974) Schistosoma mansoni: utilization of exogenous metabolites by eggs in vitro. Exp Parasitol 36:222232

Swiderski Z (1994) Origin, differentiation and ultrastructure of egg envelopes surrounding the miracidia of Schistosoma mansoni. Acta Parasitol 39:64-72

Tyler S, Tyler MS (1997) Origin of the epidermis in parasitic platyhelminths. Int J Parasitol 27:715-738

Van de Vijver KK, Deelder AM, Jacobs W, Van Marck EA, Hokke $\mathrm{CH}$ (2006) LacdiNAc- and LacNAc-containing glycans induce granulomas in an in vivo model for schistosome egg-induced hepatic granuloma formation. Glycobiology 16:237-243

Vogel H (1942) Über Entwicklung, Lebensdauer und Tod der Eier vom Bilharzia japonica im Wirtsgewebe. Dtsch Tropenmed Ztsch 46:57-91

Warren KS (1978) The pathology, pathobiology and pathogenesis of schistosomiasis. Nature 273:609-612

Wells KE, Cordingley JS (1991) Schistosoma mansoni: eggshell formation is regulated by $\mathrm{pH}$ and calcium. Exp Parasitol 73:295310

Williams DL, Asahi H, Botkin DJ, Stadecker MJ (2001) Schistosome infection stimulates host CD4(+) $\mathrm{T}$ helper cell and B-cell responses against a novel egg antigen, thioredoxin peroxidase. Infect Immun 69:1134-1141

Wilson RA (1987) Cercariae to liver worms: development and migration in the mammalian host. In: Rollinson D, Simpson AJG (eds) The biology of schistosomes: from genes to latrines. Academic, London, pp 115-146

World Health Organization (2006) Report of the Scientific Working Group meeting on Schistosomiasis. WHO, Geneva

Younossi-Hartenstein A, Hartenstein V (2000a) Comparative approach to developmental analysis: the case of the dalyellid flatworm, Gieysztoria superba. Int J Dev Biol 44:499-506

Younossi-Hartenstein A, Hartenstein V (2000b) The embryonic development of the polyclad flatworm Imogine mcgrathi. Dev Genes Evol 210:383-398

Younossi-Hartenstein A, Hartenstein V (2001) The embryonic development of the temnocephalid flatworms Craspedella pedum and Diceratocephala boschmai. Cell Tissue Res 304:295-310

Younossi-Hartenstein A, Ehlers U, Hartenstein V (2000) Embryonic development of the nervous system of the rhabdocoel flatworm Mesostoma lingua (Abilgaard, 1789). J Comp Neurol 416:461-474 